\title{
Spatio-temporal variability of behavioral patterns in hydrology in meso-scale basins of the Rhineland Palatinate (1972-2002)
}

\author{
H. Hellebrand • R. van den Bos • L. Hoffmann • \\ J. Juilleret • A. Krein • L. Pfister
}

Received: 5 July 2006 / Accepted: 2 September 2008 / Published online: 20 November 2008

(C) Springer Science + Business Media B.V. 2008

\begin{abstract}
Changes in spatio-temporal rainfall patterns have an effect on the hydrological behavior of river basins, the magnitude of the effects depending among others on the physiographic basin characteristics. To assess climate and discharge fluctuations, a visualization tool was developed as a contribution to exploratory data analysis. The tool combined statistical tests of hydro-climatological variables with physiographic basin characteristics. Test results agree with previous studies and suggested a relationship between rainfall, discharge and mean date of the annual maximum discharge on the one the hand and lithology, altitude and west to east positioning of the basins on the other hand. The visualization tool capable of combining the statistical test results with the geologic and topographic configuration of the study area and allowed a reflection on the hydro-climatological as well as spatio-temporal behavior of meso-scale basins by means of exploratory data analysis.
\end{abstract}

\section{Introduction}

Numerous studies have been devoted to changes in spatial and temporal rainfall patterns (e.g. Karl and Knight 1998; Osborn et al. 2000; Brunetti et al. 2001; Hisdal et al. 2001), as well as to the link between changes in hydrological behavior and the variability in climate (e.g. Mansell 1997; Pfister et al. 2000; Hisdal et al. 2001). Burn and Elnur (2002) advocate to focus on stream flow variables to study this link, as these variables tend to reflect an integrated response of the basin area as a whole on

H. Hellebrand $(\bowtie) \cdot$ R. van den Bos $\cdot$ L. Hoffmann · J. Juilleret · A. Krein · L. Pfister

Public Research Center-Gabriel Lippmann,

41, rue du Brill, 4422 Belvaux, Grand-Duchy of Luxembourg

e-mail: H.G.W.Hellebrand@TUDelft.nl

H. Hellebrand

Section of Hydrology, Department of Water Management, Delft University of Technology,

Delft, The Netherlands 
climate variability. Yet, land use change can also be a driving factor behind changes in discharge behavior. However, amplitude and spatial scale at which climate and land use changes are likely to affect the generation of storm runoff are equally difficult to assess (Bronstert et al. 2002). For meso-scale basins, the spatio-temporal variability of atmospheric forcing on runoff generating processes is significant and at the macro-scale, spatial distribution of rainfall or snow melt and the routing of runoff are dominant (Uhlenbrook et al. 2004), where meso- and macro-scale are defined as approximately 10-1,000 km² and larger than 1,000 km², respectively (Blöschl 1996). A spatio-temporal assessment of the hydro-climatological behavior of meso-scale basins within a macro-scale basin could give insight into their general behavior.

It is common practice to visualize spatial patterns in maps and temporal patterns in graphs. The objective of this paper is to condense maps and graphs into one tool that reflects the relationship between spatio-temporal climate fluctuations, spatiotemporal hydrologic behavior patterns and physiographic basin characteristics of meso-scale basins, located in the Mosel basin and parts of the adjacent Rhine valley. Given the large information content of such a study, the tool will be derived using exploratory data analysis, which is an advanced visual examination of the data and involves using graphs to explore, understand and present data, and is an essential component of any statistical analysis (Kundzewicz and Robson 2004). The tool is used to illustrate the hydro-climatological behavior of macro-scale basins and their sub-basins.

Pfister and Hoffmann (2001) showed that annual and seasonal rainfall patterns in the Grand Duchy of Luxembourg are characterized by a strong negative West-East gradient. An increase in winter rainfall totals and their implication for river discharge were observed since the 1970's and attributed mainly to a significant increase in the occurrence of days with westerly atmospheric circulation types (Mansell 1997; Pfister et al. 2000). Tu et al. (2005) documented the precipitation variability in the Meuse basin with respect to atmospheric circulation. Moreover, Pfister et al. (2004) showed that observed trends over the last 30 years in rainfall characteristics and maximum daily water levels during winter for nine river basins in the Grand-duchy of Luxembourg are closely linked to spatial rainfall patterns and topography. In a case study on winter rainfall regime change in temperate western European areas, Drogue et al. (2006) proved that geographical patterns show a zonal anisotropy of the winter rainfall regime change, hence implying an intensification of horizontal rainfall gradients. They also observed more contrasted westerly winter rainfall amounts in mountainous areas during the post-1979 period following the change point year of atmospheric circulation over northwestern Europe. In comparison to the study of Pfister et al. (2004) the current study area is larger, more heterogeneous and directly situated to the East adjacent to their study area. Hydrologic variables were included in order to investigate the influence of the spatio-temporal variability in rainfall trends on the hydrological behavior patterns of river basins in the area.

Douglas et al. (2000) reviewed diverse studies in the US in which the results of the trend analysis vary widely depending on the spatial scale and location of the study area. In most of these studies the non-parametric Mann-Kendall trend test was used. Burn and Elnur (2002) used this test to detect trends between hydrological and meteorological variables in 248 Canadian basins. Pfister et al. (2004) used Kendall's $\tau$ (Capéràa and Van Cutrem 1988) to calculate trends in rainfall structure over the last 50 years for the Grand Duchy of Luxembourg. 
However, according to Wijngaard et al. (2003) care must be taken when carrying out a trend analysis on meteorological station series that are prone to anthropogenic effects, i.e. gradual changes due to non-climatic causes. They suggest using different tests to detect in-homogeneities in data series, of which the standard normal homogeneity test (Alexandersson 1986) could be used to detect break point years near the beginning and end of a data series and the Pettitt test (Pettitt 1979) to detect break point years in the middle of a data series (Hawkins 1977). Brunetti et al. (2001) used a sequential form of the Kendall test to detect the approximate time of the occurrence of the trend. In order to prevent the detection of a trend by chance, analyzing hydro-climatological data series with the Kendall test, Douglas et al. (2000) applied an approach based on bootstrapping to detect cross-correlation. However, Pfister et al. (2004) stated in their study that when studying spatial variability of trends, all available measuring stations should be used, even in case of cross-correlation, due to the fact that for each station an observed trend is influenced by climatological and physiographic conditions in the embedded monitored upstream sub-basins.

It is not the intention of this study to present a detailed trend analysis of each individual basin of the study area. The objective of this study is to present a tool that reflects the hydro-climatological behavior of a large area over several decades and results are expected to agree with previous studies in this field. Furthermore, the results of the methodology should be applicable for prediction in ungauged basins.

\section{Study area and available data}

The study area consists of 70 basins (varying in size between $8 \mathrm{~km}^{2}$ and 4,011 $\mathrm{km}^{2}$ ) located in the upper Mosel basin in the Rhineland Palatinate (Germany) and covers approximately $15,000 \mathrm{~km}^{2}$ (Fig. 1). The names and numbers of the basins, together with the used physiographic and hydrological characteristics are given in Table 1. Altitudes range from $67 \mathrm{~m}$ asl at the lowest point of the Rhine valley to $816 \mathrm{~m}$ asl on the Hunsrück mid mountain region. Two successive ridges, both running from southwest to northeast, mark the contours: the Eifel and the Hunsrück; a third mid mountain range lies in the northeastern part of the study area: the Westerwald (Fig. 1).

The study area has a temperate humid climate, influenced by the Atlantic Ocean and transforms from an oceanic temperate climate to a semi-oceanic climate from west to east. Rainfall patterns are under influence of the macro relief. The average annual precipitation ranges from approximately $540 \mathrm{~mm}$ in the middle part of the study area (Rhine valley) to approximately $1,100 \mathrm{~mm}$ on the higher ridges, with an average annual precipitation of $820 \mathrm{~mm}$ for the entire study area. The average annual temperature ranges from $6^{\circ} \mathrm{C}$ for the higher ridges to $10^{\circ} \mathrm{C}$ for lower valleys, with an average annual temperature of $8.6^{\circ} \mathrm{C}$ fort the entire study area.

The study area is located mainly in the Rhenish Massif and consists largely of schist, siltstone, sandstone and quartzite of Devonian age. The northeastern part is characterized by tectonic dissections of geological strata and displays a heterogeneous geology in comparison to the remainder of the study area. The southeastern part of the study area (Pfalz and Rhine valley) consists of an alternation of sandstone, conglomerates and clay of the Buntsandstein and of tertiary sandy, silt deposits and 


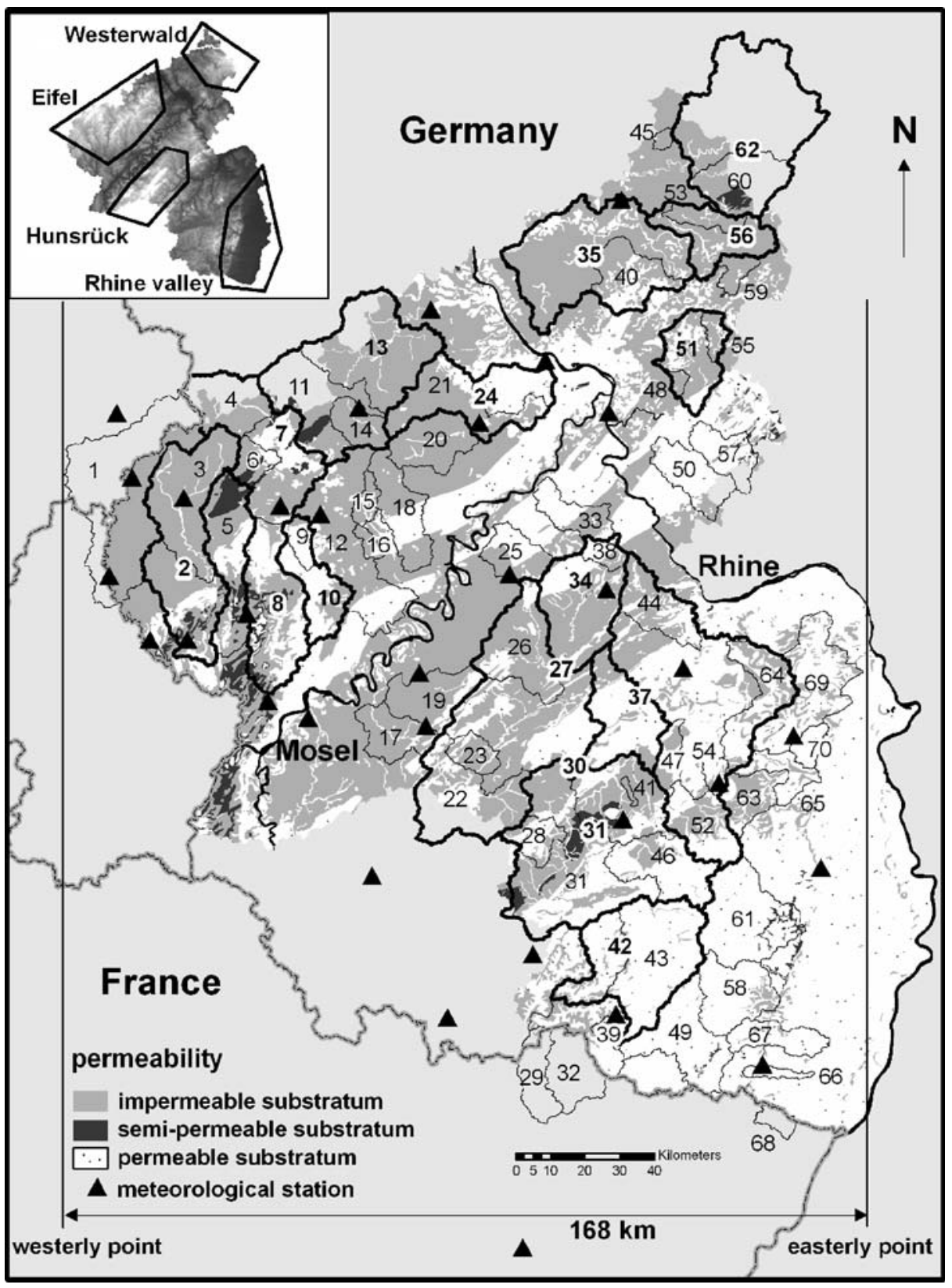

Fig. 1 Study area with numbered basins; basins with sub-basins are indicated with bold numbers and thick basin borders

quaternary Rhine terraces. The overall land use of the study area is $4 \%$ urban area, $28 \%$ cropland, $22 \%$ grassland and $46 \%$ forest. However, land use percentages vary between meso-scale basins. 


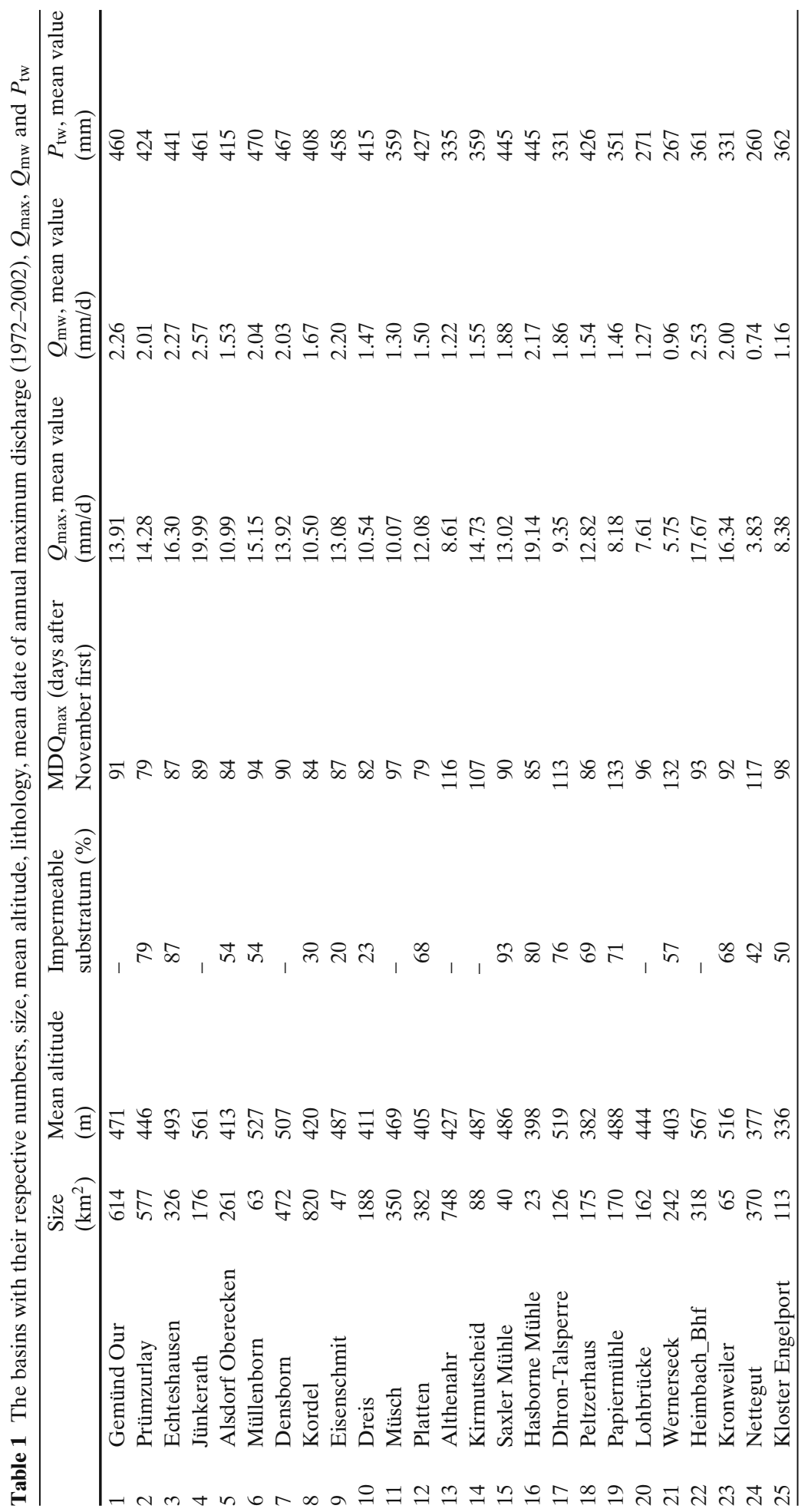




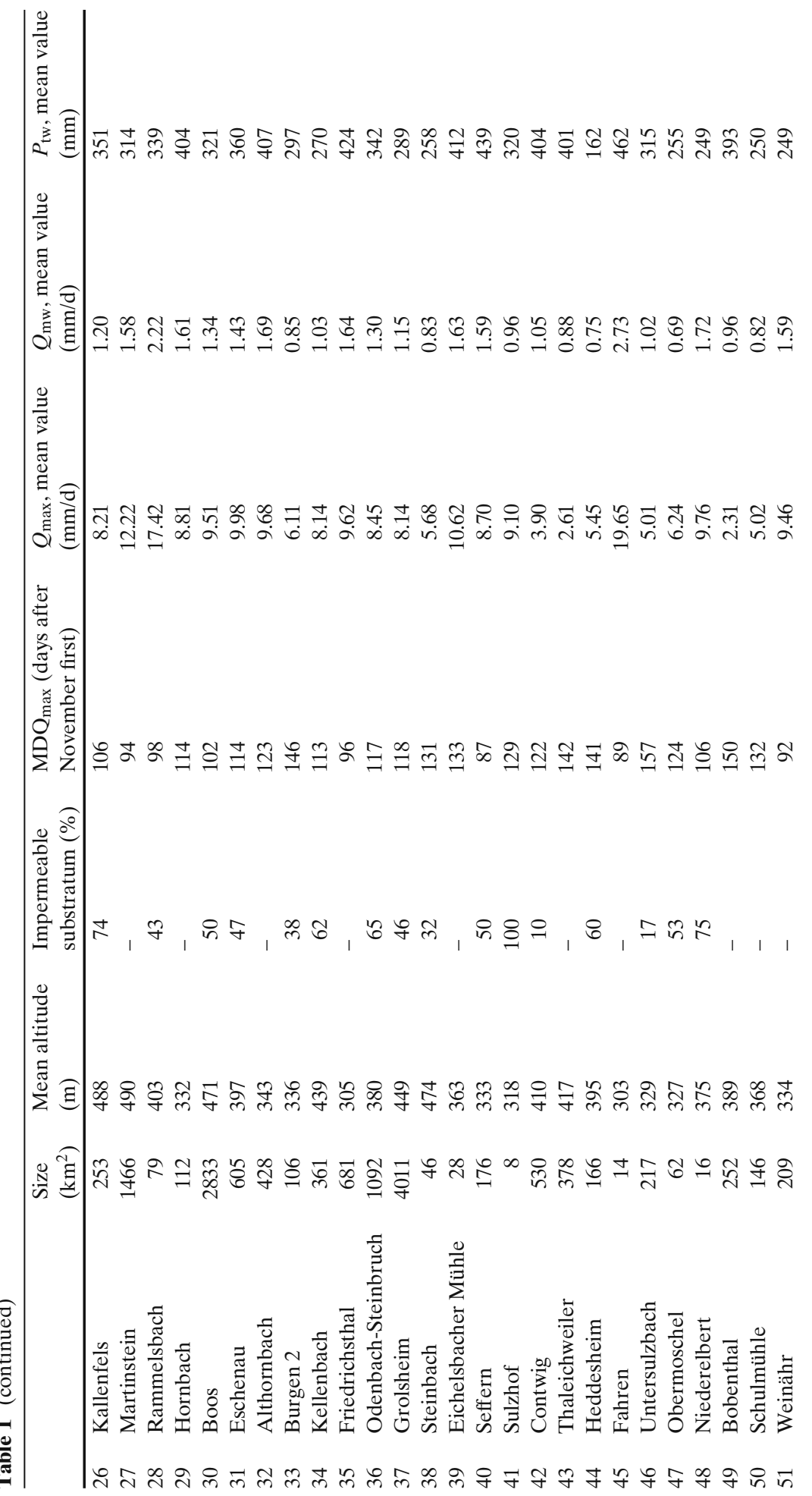




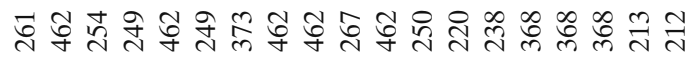

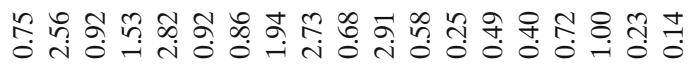

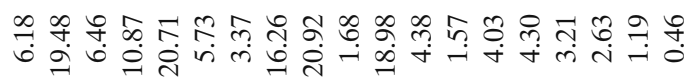

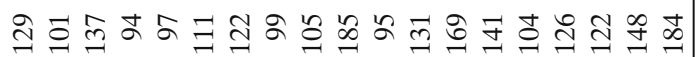

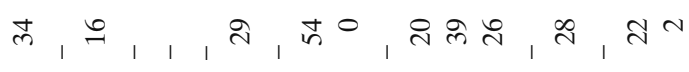

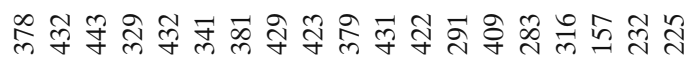

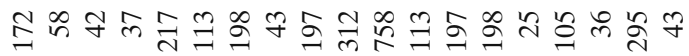

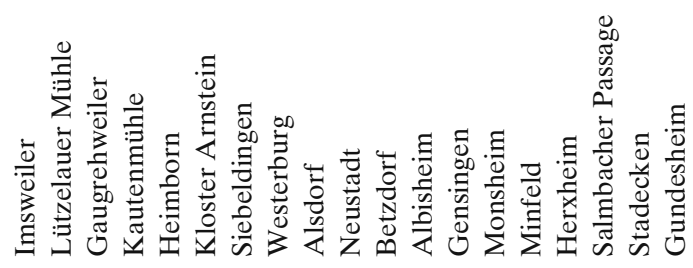

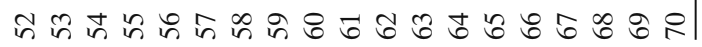


Daily rainfall values from 54 meteorological stations located throughout the study area were used. For the discharge data 70 gauging stations were available, which supplied mean daily discharge values. Seventeen basins are comprised of two or more sub-basins. No attempt was made to reconstruct natural flow regimes of rivers, which would introduce uncertainty into the discharge series. The record length used for both discharge and rainfall data series runs from November 1st 1972 until December 31st 2002: 30 years in total.

\section{Methodology}

In order to develop an assessment tool for climate variability and discharge behavior, a three-step approach was applied of which the first two steps are largely based on a study by Burn and Elnur (2002) to detect hydrological trends and variability:

1. Selection of hydro-climatological variables

2. Statistical analysis of the selected variables

3. Visualization of the spatio-temporal behavior of the selected variables

By using all available basins, whether anthropogenic influences impact or not, the hydrological reaction of a larger region will be represented. If anthropogenic effects on basins show clear trends, a detailed study on these trends could indicate to what extent anthropogenic influences are related to discharge variability.

\subsection{Selection of hydro-climatological variables}

In a study on detecting trends and variability in discharge in Canadian basins, Burn and Elnur (2002) used among others the annual mean flow $\left(Q_{\text {mean }}\right)$ and annual maximum flow $\left(Q_{\max }\right)$ of rivers and the date of the annual maximum flow to detect the hydrological response of river basins to climate variability. In addition to $Q_{\text {mean }}$ and $Q_{\max }$ the mean specific discharge $\left(Q_{\mathrm{mw}}\right)$ during the winter period (1st of October until 31st of March), total annual rainfall $\left(P_{\text {year }}\right)$, total rainfall during the winter period $\left(P_{\mathrm{tw}}\right)$ and antecedent rainfall $\left(P_{t}\right)$ before the maximum annual discharge for $t=2$ to 7 days (Table 2) were used. The spatial estimations of rainfall depth were performed using Thiessen Polygons. Furthermore, the mean date of annual maximum flow $\left(\mathrm{MDQ}_{\max }\right)$ as proposed by Burn (1997) and the standard deviation of $\mathrm{MDQ}_{\max }\left(\mathrm{STDEVMDQ} \mathrm{Q}_{\max }\right)$ to assess climatological fluctuations (Table 2) were used.

To study fluctuations in climate a classification system derived by Hess and Brezowski (1977) was selected, which describes the specific daily weather situation over Central Europe by looking at the general atmospheric circulation patterns over the whole European continent and the eastern part of the North Atlantic. In this system, the daily weather situation is classified into one of the 29 occurring classes, or so-called Grosswetterlagen (GWL). When referred to a specific GWL, a GWL $X$ is mentioned, in which $X$ stands for one of the 29 classes. Due to the fact that a GWL refers a weather situation for a specific day it is possible to link the weather situation directly to hydrological events. The classification system is used to derive a fourth climatological variable, the $\mathrm{GWL}_{t} X$, which relates rainfall to a dominating 
Table 2 Hydro-climatologicalal variables with abbreviation and units

\begin{tabular}{lll}
\hline Hydro-climatologicalal variable & Abbreviation & $\mathrm{Unit}$ \\
\hline Maximum annual specific discharge & $Q_{\max }$ & $\mathrm{L} /\left(\mathrm{TL}^{2}\right)$ \\
Mean annual specific discharge & $Q_{\text {mean }}$ & $\mathrm{L} /\left(\mathrm{TL}^{2}\right)$ \\
$\begin{array}{l}\text { Mean specific discharge during winter period } \\
\quad \text { from 01-11 until 31-03) }\end{array}$ & $Q_{\mathrm{mw}}$ & $\mathrm{L} /\left(\mathrm{TL}^{2}\right)$ \\
$\begin{array}{l}\text { Total annual rainfall } \\
\text { Total winter rainfall during winter period } \\
\quad \text { from 01-11 until 31-03) }\end{array}$ & $P_{\text {year }}$ & $\mathrm{L} / \mathrm{T}$ \\
$\begin{array}{l}\text { Mean date of maximum annual specific discharge } \\
\text { Standard deviation of the mean date of maximum } \\
\quad \text { annual discharge }\end{array}$ & $P_{\mathrm{tw}}$ & $\mathrm{L} / \mathrm{T}$ \\
$\begin{array}{l}\text { Total rainfall fallen } t=2,3,4,5,6 \text { and } 7 \text { days before date } \\
\text { of maximum annual discharge respectively }\end{array}$ & $\mathrm{MDQ}_{\max }$ & $\mathrm{T}$ \\
$\begin{array}{l}\text { Ratio between rainfall amounts due to a GWL } X \text { and } \\
\text { total rainfall amounts during } t\end{array}$ & $P_{t}$ & $\mathrm{~T}$ \\
Dominating GWL $X$, based on threshold value $v=0.5$ of $R_{t}$ & $\mathrm{GWL}_{t} X$ & $\mathrm{~L}$ \\
\hline
\end{tabular}

GWL $X$ during an antecedent period $t$ before the annual maximum flow, with $t=2$ to 7 days. To determine a dominant GWL $X$ in terms of rainfall production the ratio $R_{t}$ between rainfall amounts due to a GWL $X$ and total rainfall amounts, both occurring during the antecedent period $t$ before $Q_{\max }$ (Table 2) was used. Depending on a threshold value of $R_{t}$, which in this study was set to 0.5 , the dominating GWL $X$ was identified for period $t$.

The following basin characteristics were selected as drivers of the hydrological variables to analyze interactions with the variables: lithology, relief and basin area. Lithology was expressed in terms of permeability of the substratum and plays an essential role in transforming precipitation into runoff. Since topography plays an additional role in the distribution of rainfall (Drogue et al. 2006; Pfister et al. 2000, 2004) mean and maximum altitude as well as slope areas with an aspect facing south to north in a five-degree step were incorporated. A Principal Component Analysis (PCA) was performed to determine relationships between the physiographic basin characteristics and the hydro-climatological variables.

\subsection{Statistical analysis on the selected variables}

For each of the selected hydro-climatological variables their autocorrelation was calculated first. Next the SNHT and the non-parametric Pettitt test were applied to detect change-point years in the data series of the hydro-climatological variables (i.e. $Q_{\text {max }}, Q_{\text {mean }}, Q_{\mathrm{mw}}, P_{\text {year }}$ and $P_{\mathrm{tw}}$ ). The level of significance was set to the $1 \%$ probability level. When a change-point year occurs, it can indicate either an anthropogenic influence, like the displacement of measurement equipment, or a change in the hydro-climatological regime.

The non-parametric Kendall test as described by Capéràa and Van Cutrem (1988) was applied to the data sets of the above selected hydro-climatological variables to detect possible trends. The record length of the data sets runs from 1972 until 2002 and the level of significance was set to the $5 \%$ and $95 \%$ probability level with tau 
values of -1.66 and +1.66 , which are commonly used (Burn and Elnur 2002; Pfister et al. 2004). Results of the Kendall test were divided into four classes: a statistically significant trend, either positive or negative and a statistically non-significant trend, either positive or negative, represented by the numbers $2,-2,1,-1$, respectively.

To study a possible relationship between the location of the basins and their hydro-climatological variables and physiographic characteristics Spearman's rank correlation coefficient $r_{\mathrm{s}}$ was calculated for the basins ranked from west to east and north to south. Since westerly fluxes play an important role in the distribution of precipitation amount in the area (Pfister et al. 2004), the west to east representation of the basins was chosen. Furthermore, to investigate changes from west to east for lithology and topography, a grid was projected over the study area (cell width: $5 \mathrm{~km}$, cell length: entire stretch of the study area from south to north) starting at $0 \mathrm{~km}$ and ending at $175 \mathrm{~km}$ (most westerly and most easterly tip of the study area, respectively). For each of the cells the percentages of permeable substratum, mean altitude, maximum altitude and aspect facing south to north was calculated in a Geographical Information System (GIS). The purpose of the grid is to illustrate changes in physiographic basin characteristics to which the basins are subject to in a west to east direction. In order to combine the trend statistics with space, time and the physiographic characteristics of the basins, a visual representation of the variables with their trends and the basin characteristics was developed.

\subsection{Visual representation of the spatio-temporal behavior of the selected variables}

To represent the spatio-temporal variability of each variable a so-called variable matrix was derived. The elements of the variable matrix represent the values of hydro-climatological variables. The rows of the matrix represent the winter periods from 2002 back to 1972. The columns represent the position of the basins within the study area ranked from west to east based on the position of their respective gravity center, obtained in a GIS. Consequently, element $[1,1]$ of the variable matrix represents a value of a variable in the winter of 2001-2002 for the most westerly located basin in the study area and element $[30,70]$ represents a value of a variable in the winter of 1972-1973 for the most easterly located basin. To visualize this variable matrix, the elements (i.e. the values of the hydro-climatological variables) were classified and each class was represented by a color. To obtain a matrix suited for visualization, the basins were positioned with the same discrete interval to each other, disregarding the actual distance between the gravity centers.

A horizontal line is depicted above the variable matrices indicating the position of the basins ranked from north to south using a Grey scale, where black represents the most northerly and white the most southerly positioned basin. Results of the Kendall test are also depicted above the variable matrices, using the classes defined in Section 3.2. If a change-point year was detected in a time series of a variable according to the SNHT and/or the Pettitt test, this change point year is indicated in the variable matrix. Furthermore, the values of STDEVMDQ $\max$ are given on the right hand side of the $\mathrm{GWL}_{t} X$ variable matrix only to indicate the spread of the maximum annual flow of the study area. $M D Q_{\max }$ is classified and depicted above the $Q_{\max }$ variable matrix. A bar underneath the variable matrices indicates where the gravity center of each basin is situated with respect to the most westerly tip of the study area (i.e. $0 \mathrm{~km})$. 


\section{Results and discussion}

The results of the statistical test, the physiographic characteristics and values of the hydro-climatological variables will be visualized using the variable matrices, thus merging space and time. This creates the opportunity to analyze the results with respect to previous studies and it gives insight in how far the methodology is able to represent these results as well as its interpretation potential.

\subsection{Statistical analysis}

No autocorrelation was found in the hydro-climatological variables. The results of the SNHT, Pettitt-, and Kendall-tests, implemented on the hydrological variables, are given in Table 3. The percentage value indicates the confidence level at which the hypothesis is rejected. The values in Table 3 represent for each hydrological variable the percentages of basins that show a break for the SNHT and Pettitt test. For the Kendall test the percentage of basins with a certain type of trend is given.

According to the SNHT very few basins displayed no homogeneity at the start or end of their data series. The values of the Pettitt test suggested that there were change point years in the hydrological series of winter discharge for a number of basins. Of the 16 basins that make up the $23 \%$ of $Q_{\mathrm{mw}}, 15$ had their changepoint year in the period from 1990 till 1996 and of those 15, 12 were situated less than $90 \mathrm{~km}$ from the most westerly tip of the study area of a total study area width of $168 \mathrm{~km}$. The basins that showed a change-point year for $\mathrm{Pt}_{\mathrm{w}}$ (all around 1991-1997) were evenly distributed over the study area. For the Kendall test, most basins displayed a statistically significant positive trend for each hydro-climatological variable (Table 3). Moreover, more basins displayed a statistically positive trend in winter $Q$ means and winter $P$ totals ( $80 \%$ and $86 \%$ respectively) compared to annual $Q$ means and annual $P$ totals (71\% and $76 \%$ respectively). This difference, in combination with the results of the Pettitt test indicated that during the winter

Table 3 Percentage of basins that show a break in the hydrological variables

\begin{tabular}{cccccccccccc}
\hline & $\begin{array}{c}Q_{\max } \\
(\%)\end{array}$ & $\begin{array}{l}Q_{\text {mean }} \\
(\%)\end{array}$ & $\begin{array}{c}Q_{\text {mw }} \\
(\%)\end{array}$ & $\begin{array}{l}P_{\text {year }} \\
(\%)\end{array}$ & $\begin{array}{l}P_{\mathrm{tw}} \\
(\%)\end{array}$ & $\begin{array}{l}P_{2} \\
(\%)\end{array}$ & $\begin{array}{l}P_{3} \\
(\%)\end{array}$ & $\begin{array}{l}P_{4} \\
(\%)\end{array}$ & $\begin{array}{l}P_{5} \\
(\%)\end{array}$ & $\begin{array}{l}P_{6} \\
(\%)\end{array}$ & $\begin{array}{l}P_{7} \\
(\%)\end{array}$ \\
\hline $\begin{array}{c}\text { SNHT (1\%) } \\
\text { Pettitt (1\%)* }\end{array}$ & 3 & 4 & 0 & 1 & 1 & 1 & 0 & 0 & 0 & 0 & 0 \\
$\begin{array}{c}\text { Kendall (5\%)* } \\
\text { Significant } \\
\text { positive (2) }\end{array}$ & 78 & 71 & 80 & 76 & 86 & 77 & 78 & 76 & 58 & 70 & 76 \\
$\begin{array}{c}\text { Non-significant } \\
\text { positive (1) }\end{array}$ & 3 & 6 & 4 & 9 & 3 & 6 & 6 & 10 & 9 & 7 & 4 \\
$\begin{array}{c}\text { Non-significant } \\
\text { negative (-1) }\end{array}$ & 6 & 6 & 6 & 9 & 5 & 6 & 6 & 4 & 14 & 9 & 6 \\
$\begin{array}{c}\text { Significant } \\
\text { negative (-2) }\end{array}$ & 13 & 17 & 10 & 6 & 6 & 11 & 10 & 10 & 19 & 14 & 14 \\
\hline
\end{tabular}

The percentage values marked with asterisk indicate the confidence levels at which the hypothesis is rejected. Maximum annual discharge $\left(Q_{\max }\right)$, mean annual discharge $\left(Q_{\text {mean }}\right)$, mean winter discharge $\left(Q_{\mathrm{mw}}\right)$, total annual rainfall $\left(P_{\text {year }}\right)$, total winter rainfall $\left(P_{\mathrm{tw}}\right)$ and total rainfall fallen 2 , $3,4,5,6$ and 7 days prior to date of maximum annual discharge, $\left(P_{2}, P_{3}, P_{4}, P_{5}, P_{6}, P_{7}\right)$ given in percentages of basins 
periods from 1972 until 2002 and especially from 1990 until 1996 a significant increase of rainfall and consequently discharge has occurred in most basins. This agrees with the study of Pfister et al. (2004). During the period from 1990 until 1996 an increase of the North Atlantic Oscillation $\left(\mathrm{NAO}^{+}\right)$took place, bringing more wet oceanic air masses to the continent under a westerly circulation regime (GWL2; Pfister et al. 2000). An increase of the $\mathrm{NAO}^{+}$has been observed during the $1980 \mathrm{~s}$ as well. Although winter rainfall totals did not differ that much when comparing the two periods, the GWL2 was markedly more dominant in causing high precipitation amounts during 1990-1996 (see later). The difference in values of the Pettitt test between $P_{2,3,4}\left(14 \%, 16 \%\right.$ and $11 \%$ respectively) and $P_{5,6,7}(6 \%, 1 \%$ and $3 \%$ respectively) are caused by smoothing effects of a longer time series.

\subsection{Spatio-temporal variability}

Figures 2, 3 and 4 visualize the values of $P_{\mathrm{tw}}, Q_{\mathrm{mw}}$ and $Q_{\max }$ according to step 3 of the above-described methodology. It should be noted that each value in the variable

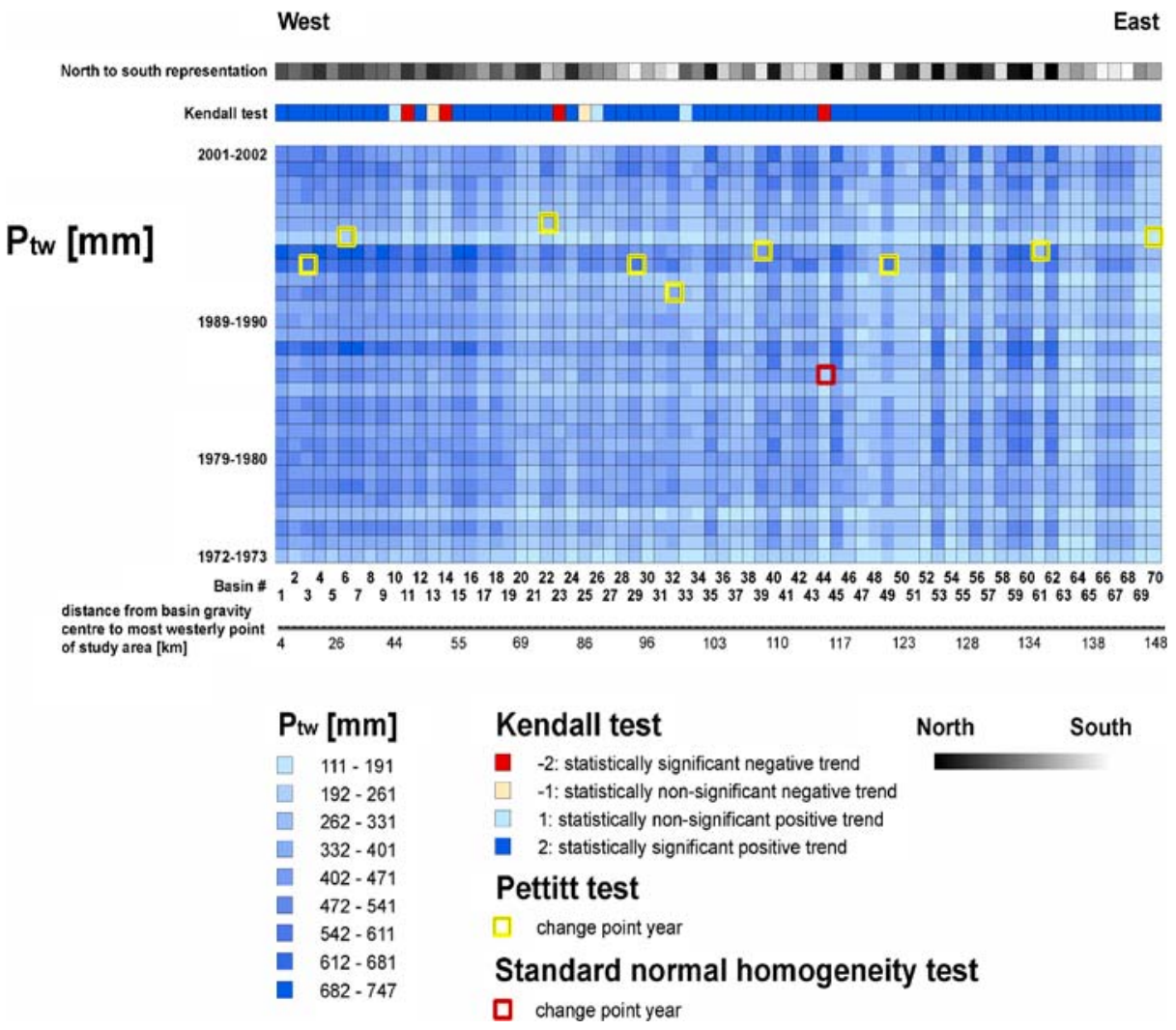

Fig. 2 Visual representation of $P_{\text {tw }}$ fallen in the basins of the study area from 1972 to 2002 (basins are grouped from west to east and the numbers correspond to those given in Fig. 1) 


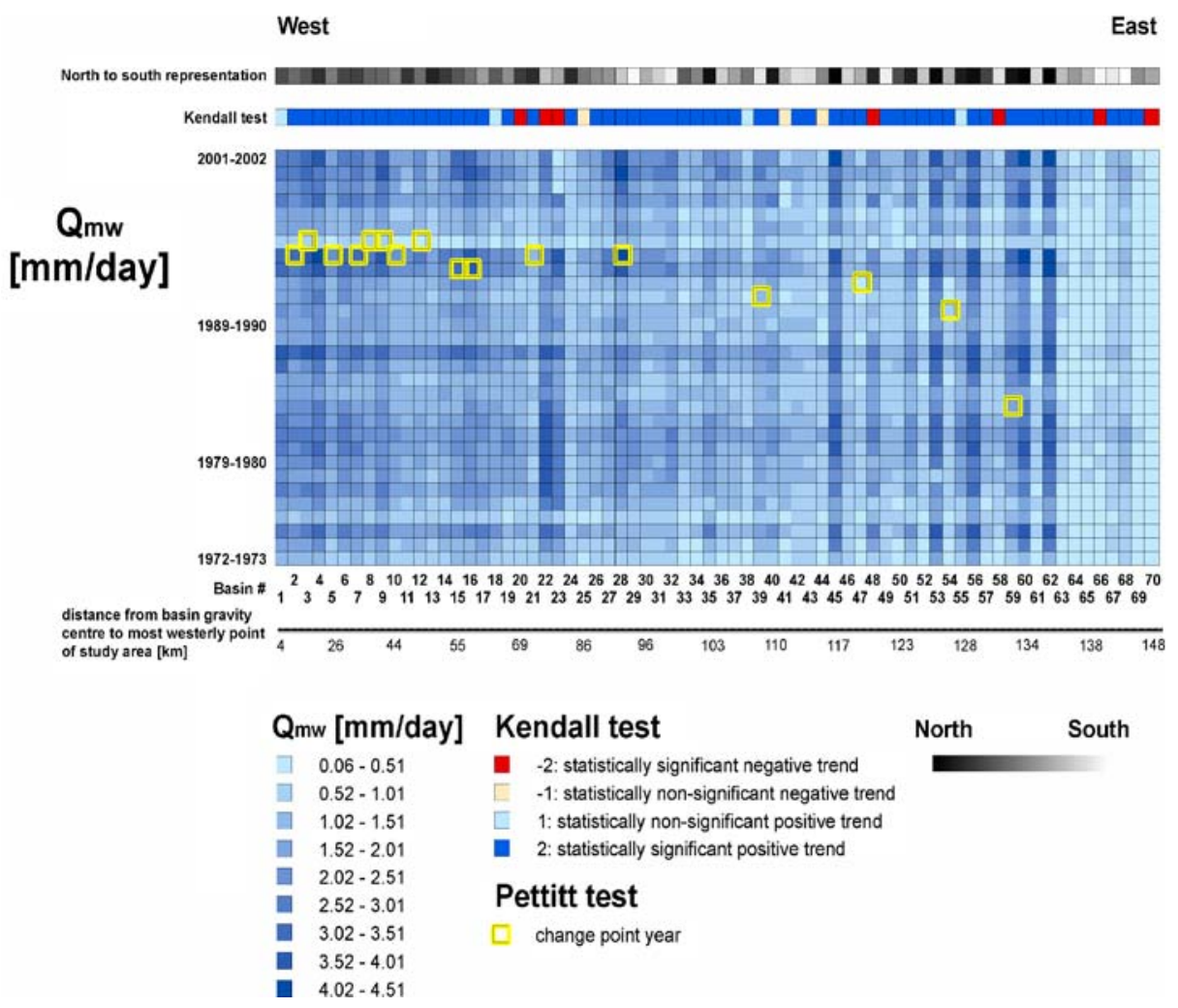

Fig. 3 Visual representation of $Q_{\mathrm{mw}}$ of the basins of the study area from 1972 to 2002 (basins are grouped from west to east and the numbers correspond to those given in Fig. 1)

matrix of $Q_{\max }$ stands for a single event occurring during a single day. The results of the statistical tests can be depicted consistently in Figs. 2-4.

Since discharge is a result of precipitation, Figs. 3 and 4 have a strong visual resemblance with Fig. 2. The following features have been observed in all three figures:

(1) A gradient of decreasing precipitation as well as discharge from northwest to southeast.

(2) Five basins (basins 53, 56, 59, 60 and 62) showed high values of $P_{\mathrm{tw}}$ where the surrounding basins showed lower values of $P_{t w}$ and six basins (basins 45, 53, 56, 59, 60 and 62) showed high values of $Q_{\mathrm{mw}}$ and $Q_{\max }$ where the surrounding basins showed considerably lower values.

(3) Two years (1993-1994 and 1994-1995) of very high $P_{\text {tw }}$ and $Q_{\text {mw }}$ values for almost the entire study area and a period of high $Q_{\max }$ values from 1991-1992 until 1994-1995.

(4) Two years (1975-1976 and 1995-1996) with low $P_{\mathrm{tw}}, Q_{\mathrm{mw}}$ and $Q_{\mathrm{max}}$ values.

(1) The gradient of decreasing precipitation was in agreement with findings of Drogue et al. (2006). Results of the PCA showed that $Q_{\max }$ and $Q_{\mathrm{mw}}$ of the basins are strongly correlated to the impermeable substratum (correlation coefficients 


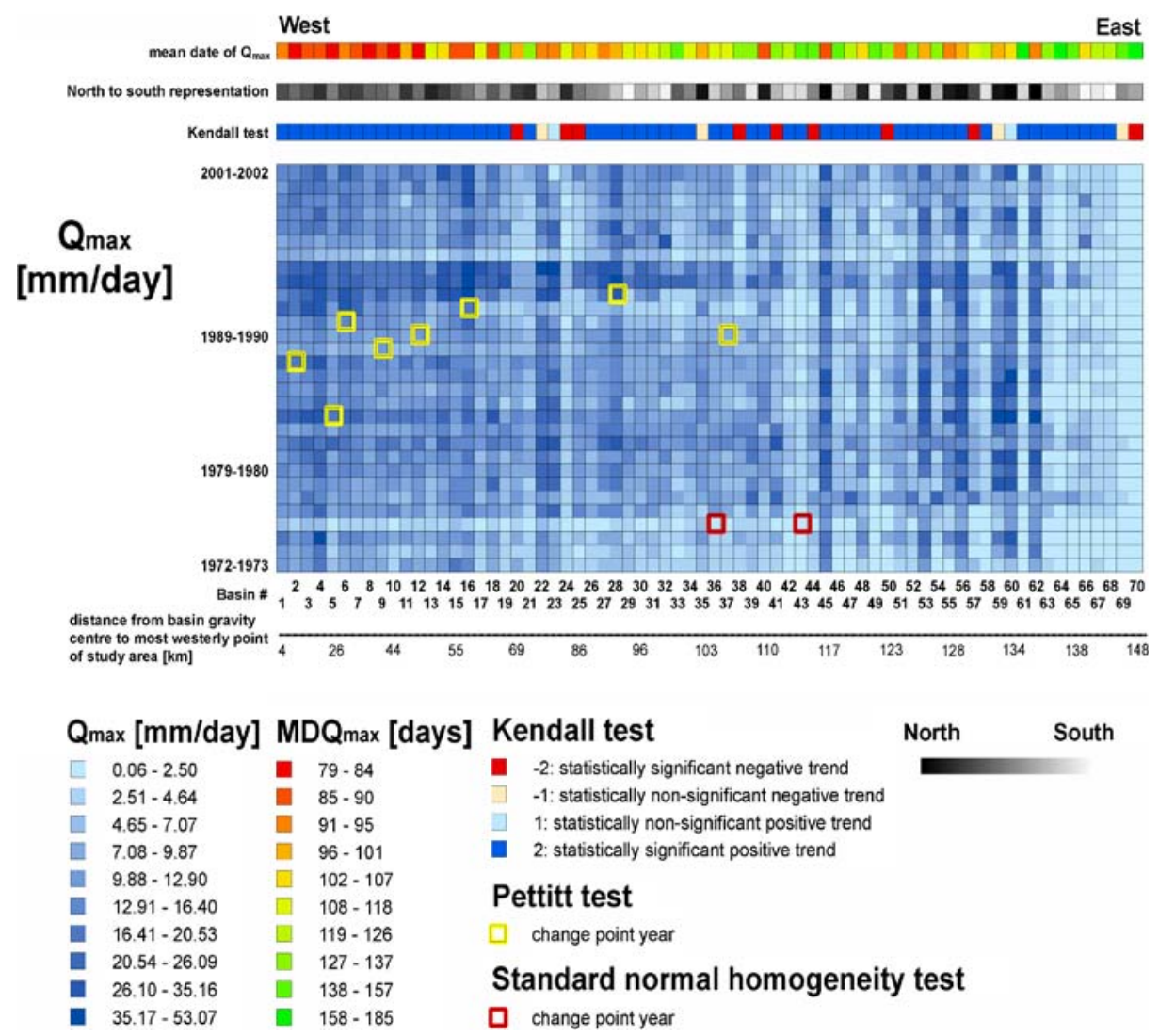

Fig. 4 Visual representation of $Q_{\max }$ in the basins of the study area from 1972 to 2002 (basins are grouped from west to east and the numbers correspond to those given in Fig. 1)

between $Q_{\max }, Q_{\mathrm{mw}}$ and the percentage of impermeable substratum are 0.80 and 0.77 , respectively). Mean altitude had a weak correlation with the variables. The basin size and the surface of the slopes facing south to north with a five-degree step had no correlation. The $M \mathrm{MQ}_{\max }$ was inversely correlated to the variables. The Spearman's $r_{\mathrm{s}}$ statistic confirmed the gradient of $Q_{\max }$ and $Q_{\mathrm{mw}}$. Test results are listed in Table 4. $Q_{\max }, Q_{\mathrm{mw}}$ and altitude had negative correlation coefficients, which indicated a decrease of these values when moving from west to east and from

Table 4 Spearman's rank correlation coefficient $r_{s}$ between basin ranking and hydroclimatologicalal variables and physiographic characteristics

\begin{tabular}{lllllll}
\hline & $Q_{\max }$ & $Q_{\mathrm{mw}}$ & $P_{\mathrm{tw}}$ & Area & $\mathrm{MDQ}_{\max }$ & Mean altitude \\
\hline All basins from west to east & $\mathbf{- 0 . 5 1}$ & $\mathbf{- 0 . 4 9}$ & -0.41 & -0.27 & $\mathbf{0 . 6 1}$ & $\mathbf{- 0 . 6 1}$ \\
All basins from north to south & $\mathbf{- 0 . 5 2}$ & $\mathbf{- 0 . 4 7}$ & -0.26 & -0.01 & $\mathbf{0 . 5 0}$ & -0.22 \\
$\begin{array}{l}\text { Basins from west to east } \\
\text { without the Westerwald }\end{array}$ & $\mathbf{- 0 . 7 8}$ & $\mathbf{- 0 . 7 5}$ & $\mathbf{- 0 . 6 5}$ & -0.29 & $\mathbf{0 . 6 9}$ & $\mathbf{- 0 . 6 9}$ \\
\hline
\end{tabular}

Significant values are given in bold 
north to south, respectively. $\mathrm{MDQ}_{\max }$ had a positive correlation, which indicated that the date of the maximum annual flow occurred later in winter when moving from west to east and from north to south. In Fig. 5 the results of the GIS calculation of the raster projection are illustrated. A gradual decrease of the mean and maximum altitude and a gradual increase of the permeable substratum occur when moving from west to east. The slope with an aspect facing south to north does not show such a change. Regarding slopes with aspects that face southwest to northwest and slopes with aspects facing west to north, the results did not differ from the pattern observed in Fig. 5 for south-north slopes. The above-described results presume a relation between position, physiographic characteristics and reaction of the basins to climate variability.

Since over the last decades the increase in winter rainfall is to a large extent supposed to be attributable to an increase in westerly atmospheric circulations (Pfister et al. 2000) and since topography is influencing precipitation (Drogue et al. 2006; Pfister et al. 2000, 2004), the Figs. 2-4 depict these findings quite well. The gradient in precipitation and discharge could be endorsed to orographic effects imposed by the two successive Eifel and Hunsrück ranges, running more or less from southwest to northeast. Basins belonging to the former range show higher values for precipitation and discharge than basins belonging to the latter. The remaining basins, except the aforementioned six (see point 2), are situated in the Rhine and Mosel valleys and are on the leeward side of the ranges, hence displaying lower values of precipitation and discharge.

(2) The basins with markedly higher precipitation and discharge than their neighboring basins (based on the west to east projection) were the most northeasterly positioned basins of the study area and belong to the Westerwald, where discharge values were as high as the most westerly situated basins of the study area (basins 1

Fig. 5 Altitude (mean and maximum), percentage of permeability and percentage of aspect (south to north) of $5 \mathrm{~km}$ strips projected across the study area from west to east

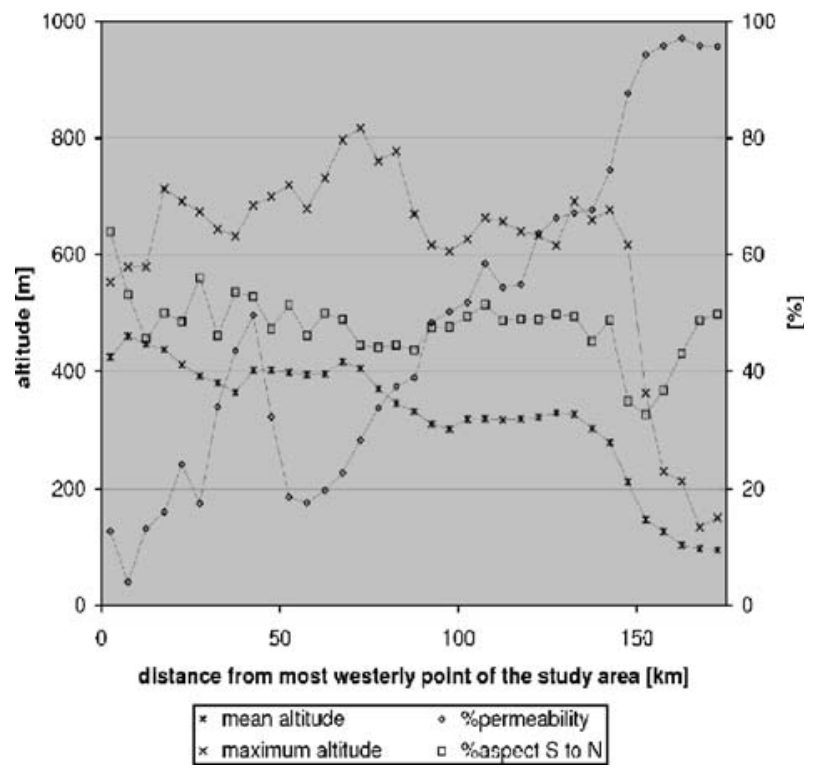


to 21). This is explained by the fact that there is no mountain range of any significance in front of the Westerwald basins to attenuate precipitation amounts, contrary to easterly-located basins. The correlation coefficient of the Spearman's rank test for the west-to-east ranking increased markedly when the Westerwald basins were omitted from the calculation (Table 4). It also explains the anomaly in Figs. 2-4 caused by the Westerwald basins. Basin 45 had a considerably higher $Q_{\mathrm{mw}}$ and $Q_{\max }$ than its neighboring basins, but the values for $P_{\mathrm{tw}}$ were more or less the same. A high percentage of impermeable substratum of the basin explains this, as it induces higher values of discharge.

(3) The two winters of increased $P_{\mathrm{tw}}$ and $Q_{\mathrm{mw}}$ values and the period (1991-1995) of increased $Q_{\max }$ occurred at exactly the same time as the increase of the $\mathrm{NAO}^{+}$ (Pfister et al. 2000). However, the 1991-1995 period provided a more pronounced $Q_{\max }$ than for the two years of increased $Q_{\mathrm{mw}}$. Since the difference is probably linked with the GWL during this period, it may only be investigated and explained using a more detailed rainfall data than that available in this study.

(4) The two winters displaying low values of the hydro-climatological variables were 1975-1976 and 1995-1996. These low values are related to the fact that both summer and winter of 1975-1976 were extremely dry as well as the winter of 19951996. The winters were dominated by cold dry air masses intruding from the North.

Regarding the Kendall test results depicted in the visualization tool, the spatial distribution of the few basins that showed a statistically significant negative trend for $P_{\mathrm{tw}}, Q_{\mathrm{mw}}$ and $Q_{\mathrm{max}}$ did not give an unequivocal result. Compared to $P_{\mathrm{tw}}$ and $Q_{\mathrm{mw}}$, only basins with relatively low values for $Q_{\max }$ showed a statistically significant negative trend. For these basins, the 1991-1995 period of increased $Q_{\max }$ was less pronounced or totally lacking. There were eight basins where this increase $Q_{\max }$ was lacking too, but still gave a statistically significant positive result of the test (i.e. basins 43, 49, 58, 61, 64, 66, 67 and 68, Fig. 4). All these basins, except basin 64 , are located in the southeastern part of the study area and have a predominantly permeable substratum (Fig. 1). Taking into account the low amounts of rainfall due to the orographic effects in combination with a permeable substratum, these basins have a more gentle discharge regime with a low ratio of mean monthly maximum discharge versus mean monthly minimum discharge (values ranging between 2.2 and 7.2). For the entire study area a minimum value of 2.2, an average value of 15.4 and a maximum of value of 66 of this ratio were calculated. Considering this, either the period from 1993 until 1995 with increased winter rainfall strongly influenced the results of the Kendall test for $Q_{\max }$, or the test was seemingly very sensitive to minor differences in values of $Q_{\max }$.

The results of the Pettitt test gave the impression that a change point did occur between 1993 and 1996 for the Eifel region of the study area. However, the results of the visualization (Figs. 2-4) indicated 2 years of increased $P_{\mathrm{tw}}$ and $Q_{\mathrm{mw}}$ and two to three years of increased $Q_{\mathrm{max}}$, followed by a year of low values of $P_{\mathrm{tw}}, Q_{\mathrm{mw}}$ and $Q_{\max }$. Since westerly fluxes hit the Eifel Mountain range first and induce more rainfall and due to the fact that the lithology of the Eifel is dominantly impermeable (meaning that discharge is more susceptible to rainfall fluctuations), the impact of fluctuations in rainfall was more pronounced in this region. Therefore, the outcome of the Pettitt test, especially for $Q_{\mathrm{mw}}$, could be induced by a succession of random events in precipitation (two years of high values followed by a year of low values) as opposed to a change-point year. 
The value of $\mathrm{MDQ}_{\max }$ (the most upper line) in Fig. 4 depicts a gradient from west to east and also from north to south. The basins of the Eifel and the Westerwald had a mean value of $\mathrm{MDQ}_{\max }$ between 79 and 105 days after November 1 (except basins 13, 21 and 24). The basins with the highest value of the mean date (between 122 and 185 days after November 1) were all situated in the Rhine valley (except basin 66 having a $\mathrm{MDQ}_{\max }$ of 106 days). The values of $\mathrm{MDQ}_{\max }$ of the Hunsrück basins were in-between. This difference was attributed to the fact that the more westerly located basins have a combination of impermeable substratum and more winter rainfall, hence triggering the maximum annual flow earlier in the winter season. The more easterly located basins have a more permeable substratum and receive less rainfall, hence needing a longer period to obtain their saturation state and produce the annual $Q_{\max }$ (see also the results of Fig. 5 concerning altitude and permeability). Combining the lower values in rainfall and a later occurrence of $\mathrm{MDQ}_{\max }$ suggested a slightly different climatological regime for these basins compared to the basins of the Eifel and Westerwald. The differences in discharge, lithology and topography suggested a

West

East

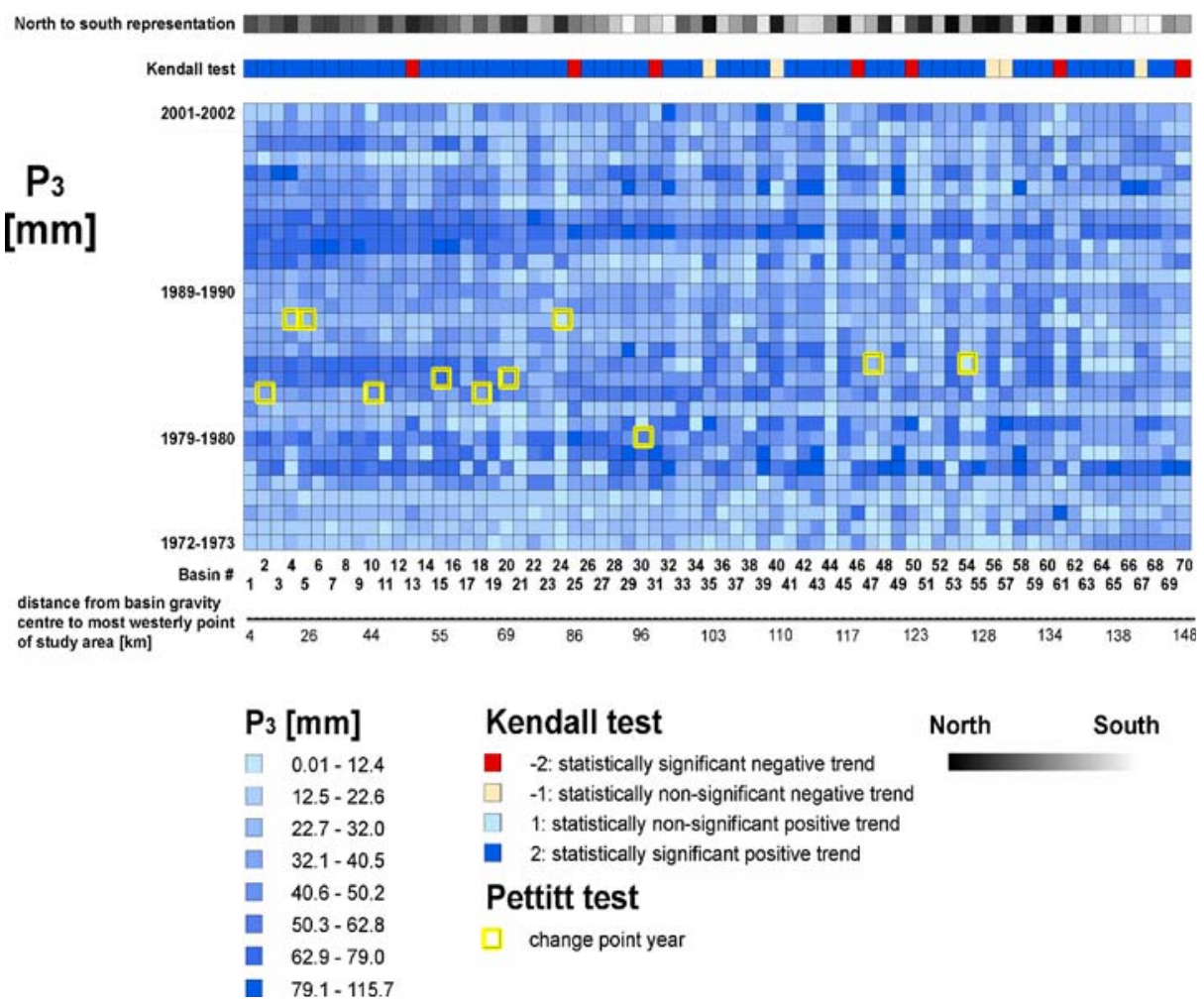

Fig. 6 Visual representation of $P_{3}$ (total rainfall fallen 3 days prior to $Q_{\max }$ ) in the basins of the study area from 1972 to 2002 (basins are grouped from west to east and the numbers correspond to those given in Fig. 1) 
slightly different hydrological behavior of these basins in the Rhine valley compared to the rest of the basins.

\subsection{Climatological fluctuations}

In Figs. 6 and 7 the visualizations of the total rainfall, fallen 3 days $\left(P_{3}\right)$ prior to $Q_{\max }$ and the visualization of $\mathrm{GWL}_{3} X$ are given. Only the differences of these matrices with $P_{7}$ and $\mathrm{GWL}_{7} X$ are shown to provide an assessment of the influence of antecedent rainfall on $Q_{\max }$. The variable matrices of the other antecedent rainfall periods and dominating $\mathrm{GWL}_{t} X$, gave similar results.

The visualized patterns of $P_{\mathrm{tw}}$ in Fig. 2 and of $P_{3}$ in Fig. 6 showed no clear resemblance. The mean value of the correlation coefficient between $P_{\mathrm{tw}}$ and $P_{3}$ for the basins over the 30 years was 0.35 , which indicated only very low correlation. The difference in rainfall quantities between $P_{3}$ and $P_{7}$ is on average $65 \%$ per basin per year. This means that of all the rainfall fallen 7 days prior the of $Q_{\max }, 65 \%$ falls during the 3 days before $Q_{\max }$ and as a result causing a rather abrupt occurrence of $Q_{\max }$ in the study area. For the annual 1, 5 and 10 maximum events of the basins, $67 \%, 63 \%$ and $57 \%$, respectively could be attributed to a $\mathrm{GWL}_{3} 2$. Furthermore, on average, $14 \%$ of the days during summer have a GWL2 against $20 \%$ of the days

West East

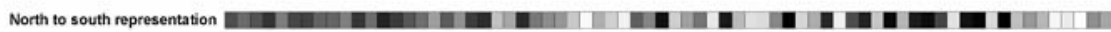

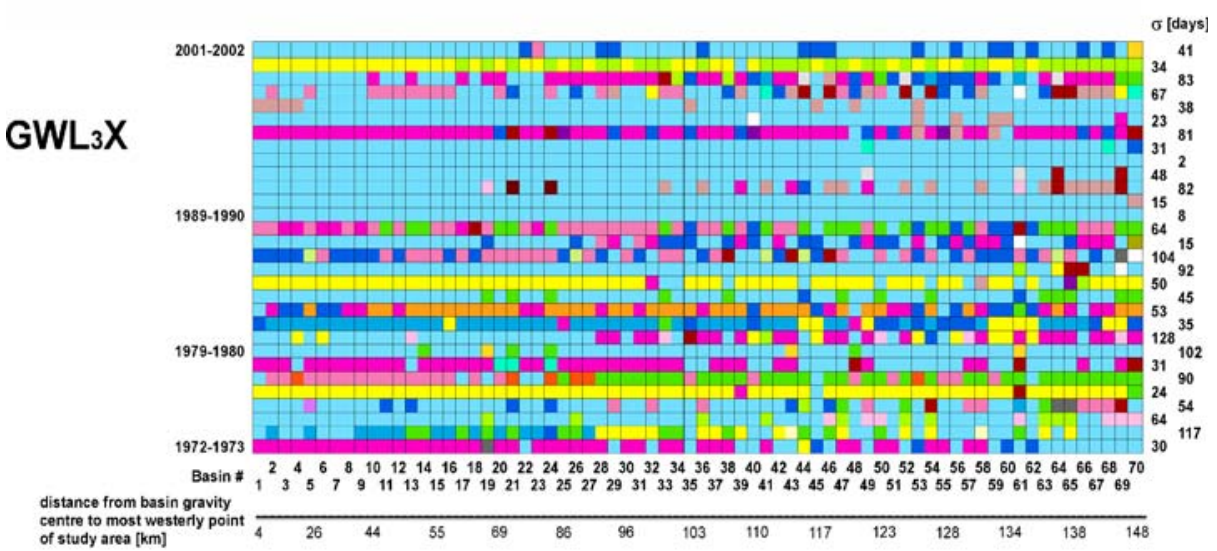
of study area $[\mathrm{km}]$

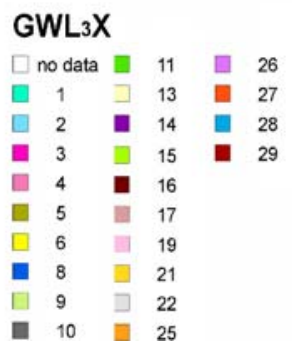

Fig. 7 Visual representation of $\mathrm{GWL}_{3} X$ in the basins of the study area from 1972 to 2002 (basins are grouped from west to east and the numbers correspond to those given in Fig. 1) 
during winter. When looking at Fig. 7, the influence of $\mathrm{GWL}_{3} 2$ on $Q_{\max }$ is apparent. For the total study period, in half of the basins $Q_{\max }$ were induced by the $\mathrm{GWL}_{3} 2$. The same holds for the $\mathrm{GWL}_{7} 2$. Moving from west to east over the study area, the influence of the westerly circulation patterns diminishes, as clearly seen in higher variation of $\mathrm{GWL}_{3} X$ ratios in Fig. 7.

The two lowest values of STDEVMDQ ${ }_{\max }$ were 2 and 8 days. They occurred in the periods of 1993-1994 and 1989-1990, respectively. In both periods for all basins $Q_{\max }$ was induced by $\mathrm{GWL}_{3} 2$ (Fig. 6). When evaluating the $\mathrm{GWL}_{7} \mathrm{X}$, all $Q_{\max }$ were $\mathrm{GWL}_{7} 2$ induced except for basin 62 , which had a $\mathrm{GWL}_{7} 17$. This meant that a rainfall event caused by a westerly flux is capable of producing the annual maximum discharge in the entire study period, implying furthermore that the rivers in all the basins reached their peak during the same event.

\section{Conclusion}

The objective of this study was to present a tool that incorporates results of statistical tests, hydro-climatological time series and physiographic basin characteristics by means of exploratory data analysis. The results of the statistical tests were in agreement with existing literature on the topic and could be depicted very well in the visualization tool. The results of the PCA and of the raster analysis suggested a relationship between rainfall, discharge and mean date of the annual maximum discharge on the one hand and the lithology, the altitude and the west to east positioning of a basin on the other hand. The tool reflected this as well. The geological configuration of the study area is such that the basins with the highest percentage of impermeable substratum receive also the highest amount of precipitation and vice versa, which is clearly reflected in the outcome of the Spearman's rank test and was illustrated in the matrix. The values of the mean date of the annual maximum discharge, which are closer to the start of the winter season for the westerly basins than for the easterly basins were also reflected in the matrix and could be explained by the geological and spatial distribution of the basins. The GWL2 played an important role in generating $\mathrm{Q}_{\max }$ during the study period and was of major importance for triggering flood events. Furthermore, rainfall induced $Q_{\max }$ in a majority of the cases in 3 days but is prone to fluctuations in climate. Spearman's rank correlation coefficient $\mathrm{r}_{s}$ gave significant negative results for $Q_{\max }, Q_{\mathrm{mw}}$ and mean altitude and a significant positive result for $\mathrm{MDQ}_{\max }$. The visual representations of $Q_{\max }$ and $Q_{\mathrm{mw}}$ were in agreement with the test results.

It was possible to use a visualization matrix in combination with trend and correlation analyses to increase our understanding of the spatio-temporal hydroclimatological behavior of a macro-scale area comprised of 70 meso-scale basins. Furthermore, the methodology could be suitable as an initial approach for predictions in ungauged basins. The application of the methodology to other regions for hydro-climatological analysis will be investigated further.

Acknowledgements This study was carried out in the framework of the INTERREG IIIB WaReLa project and the CLIMAT project funded by the Luxembourg National Research Fund (FNR). The authors would like to thank the State Office for Water Affairs Rhineland Palatinate (LfW) and especially N. Demuth for supplying the discharge data used in this study. Furthermore, the authors would like to thank the anonymous reviewers for their useful comments and especially A. Moquet, C. Wagner and M. de Wit for their valuable contribution. 


\section{References}

Alexandersson H (1986) A homogeneity test applied to precipitation data. J Climatol 6:661-675

Blöschl G (1996) Scale and scaling in hydrology. Wiener Mitteilungen, Wasser-Abwasser-Gewässer, 132, Wien, Österreich

Bronstert A, Niehoff D, Bürger G (2002) Effects of climate and land use change on storm runoff generation: present knowledge and modelling capabilities. Hydrol Proced 16:509-529

Brunetti M, Colacino M, Maugeri M, Nanni T (2001) Trends in the daily intensity of precipitation in Italy from 1951 to 1996. Int J Climatol 21:299-316

Burn DH (1997) Catchment similarity for regional flood frequency analysis using seasonality measures. J Hydrol 202:212-230

Burn DH, Elnur MA (2002) Detection of hydrologic trends and variability. J Hydrol 255:107-122

Capéràa P, Van Cutrem B (1988) Méthodes et modèles en statistique non-paramétrique - exposé fondamental. Presses de l'Université de Laval, Bordas

Douglas EM, Vogel RM, Kroll CN (2000) Trends in floods and low flows in the United States: impact of spatial correlation. J Hydrol 240:90-105

Drogue G, Wagner C, Mahr N, Hoffmann L, Pfister L (2006) Topography and recent winter rainfall regime change in temperate western European areas: a case study in the Rhine-Meuse Basin. Int J Climatol 26:785-796

Hawkins M (1977) Testing a sequence of observations for a shift in location. J Am Stat Assoc 72: 180-186

Hess P, Brezowski H (1977) Katalog der Grosswetterlagen Europas. Ber Deutsch Wetterd 15:1-14

Hisdal H, Stahl K, Tallaksen LM, Demuth S (2001) Have streamflow droughts in Europe become more severe and frequent? Int J Climatol 21:317-333

Karl TK, Knight RW (1998) Secular trends of precipitation-amounts, frequency and intensity in the United States. Bull Am Meteorol Soc 79:231-241

Kundzewicz Z, Robson A (2004) Change detection in hydrological records-a review of the methodology. Hydrol Sci 49:7-19

Mansell MG (1997) The effect of climate change on rainfall trends and flooding risk in the west of Scotland. Nordic Hydrol 28:37-50

Osborn TJ, Hulme M, Jones PD, Basnett TA (2000) Observed trends in the daily intensity of United Kingdom precipitation. Int J Climatol 20:347-364

Pettitt AN (1979) A non-parametric approach to the change-point detection. Appl Stat 28:126-135

Pfister L, Hoffmann L (2001) Evidence of a climate-induced change in maximum streamflow of the Alzette river (Grand Duchy of Luxembourg). In: Krabe P, Herpertz D (eds) Ermittlung hydrometeorologischer Referenzbedingungen für die Einschätzung der Hochwassergefährdung in grossen Flusseinzugsgebieten, CHR - report I, vol 20. Germany, pp 83-94

Pfister L, Humbert J, Hoffmann L (2000) Recent trends in rainfall-runoff characteristics in the Alzette river basin, Luxembourg. Clim Change 45:323-337

Pfister L, Drogue G, El Idrissi A, Iffly J-F, Poirier C, Hoffmann L (2004) Spatial variability of trends in the rainfall-runoff relationship: a mesoscale study in the Mosel basin. Clim Change 66:67-87

Tu M, de Laat P, Hall M, de Wit M (2005) Precipitation variability in the Meuse basin in relation to atmospheric circulation. Water Sci Technol 51-55:5-14

Uhlenbrook S, Roser S, Tilch N (2004) Hydrological process representation at the meso-scale: the potential of a distributed, conceptual catchment model. J Hydrol 291:278-296

Wijngaard JB, Klein Tank AMG, Können GP (2003) Homogeneity of 20th century European daily temperature and precipitation series. Int J Climatol 23:679-692 